\title{
A retrospective study of surgical treatment and outcome among women with adnexal torsion in eastern Taiwan from 2010 to 2015
}

\author{
Ci Huang ${ }^{1}{ }^{\text {, }}$ Mun-Kun Hong ${ }^{1}$ ， Tang-Yuan Chu ${ }^{1}$ ， Dah-Ching Ding ${ }^{\text {Corresp. }}{ }^{1,2}$ \\ 1 Department of Obstetrics and Gynecology, Hualien Tzu Chi Hospital, Buddhist Tzu Chi Medical Foundation; Tzu Chi University, Hualien, Taiwan, Taiwan \\ 2 Institute of Medical Sciences, Tzu Chi University, Hualien, Tawian, Taiwan \\ Corresponding Author: Dah-Ching Ding \\ Email address: dah1003@yahoo.com.tw
}

Background. Adnexal torsion is a gynecologic emergency that requires surgical treatment. In this study, we reviewed the surgical outcomes of women with adnexal torsion in eastern Taiwan (Hualien county, area $4629 \mathrm{~km}^{2}, 330,000$ residents).

Methods. This retrospective study included 42 women diagnosed with surgically proven adnexal torsion from January 1, 2010, to September 31, 2015. We compared the symptoms, objective findings, and surgical outcomes of patients who underwent laparotomy or laparoscopy.

Results. The laparoscopy and laparotomy groups included 27 and 15 patients, respectively. The most common symptom and sign was abdominal pain, followed by nausea and vomiting. In all patients, an adnexal tumor was detected through ultrasound. The median and range of time from admission to surgery was 1.5 (1-11.5) and 1.0 (1-11) hours in the laparotomy and laparoscopy groups, respectively. Compared with those undergoing laparotomy, the smaller tumor size [7 (4.2-10) vs. $10(7-17) \mathrm{cm}]$ and shorter hospital stay [4 (2-8) vs. 6 (3-9) days] in patients undergoing laparoscopy were significantly noted, respectively $(\mathrm{P}<0.01)$. No differences were observed in age, operative time, and blood loss between both groups. The surgeries performed were mostly detorsion with cystectomy and adnexectomy. The most common pathology was a simple ovarian cyst, followed by teratoma. Regarding the surgical types, older age is the only risk factor for radical surgery.

Discussion. Acute onset of abdominal pain with a presenting ovarian tumor is the most common feature of adnexal torsion. Laparoscopic surgical group showed a small tumor size and a short hospital stay than laparotomy. Older age is the risk factor for radical surgery. 
19

20

21 torsion in eastern Taiwan from 2010 to 2015

(3)

\title{
A retrospective study of surgical treatment and outcome among women with adnexal
}

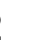

\section{torsion in eastern Taiwan from 2010 to 2015}

\author{
Ci Huang ${ }^{1}$, Mun-Kun Hong ${ }^{1,2}$, Tang-Yuan Chu ${ }^{1,2}$, Dah-Ching Ding ${ }^{1,2^{*}}$
}

${ }^{1}$ Department of Obstetrics and Gynecology, Hualien Tzu Chi Hospital, Buddhist Tzu Chi

Medical Foundation; Tzu Chi University, Hualien, Taiwan, ROC

${ }^{2}$ Institute of Medical Sciences, Tzu Chi University, Hualien, Taiwan, ROC

7

*Corresponding author:

8

Dr. Dah-Ching Ding

9

Department of Obstetrics and Gynecology

10
Hualien Tzu Chi Hospital, Buddhist Tzu Chi Medical Foundation

(1)
Tzu Chi University 707, Chung-Yang Rd., Sec. 3, Hualien City, Hualien, Taiwan, R.O. C.
Tel: +88638561825 ext. 2228
Fax: +88638577161
Email: dah1003@yahoo.com.tw

Running title: Surgical treatment of adnexal torsion 


\section{Abstract}

23 Background. Adnexal torsion is a gynecologic emergency that requires surgical treatment. In

24 this study, we reviewed the surgical outcomes of women with adnexal torsion in eastern Taiwan

25 (Hualien county, area $4629 \mathrm{~km}^{2}, 330,000$ residents).

26 Methods. This retrospective study included 42 women diagnosed with surgically proven adnexal

27 torsion from January 1, 2010, to September 31, 2015. We compared the symptoms, objective

28 findings, and surgical outcomes of patients who underwent laparotomy or laparoscopy.

29 Results. The laparoscopy and laparotomy groups included 27 and 15 patients, respectively. The

30 most common symptom and sign was abdominal pain, followed by nausea and vomiting. In all

31 patients, an adnexal tumor was detected through ultrasound. The median and range of time from

32 admission to surgery was $1.5(1-11.5)$ and $1.0(1-11)$ hours in the laparotomy and laparoscopy

33 groups, respectively. Compared with those undergoing laparotomy, the smaller tumor size [7

$34(4.2-10)$ vs. $10(7-17) \mathrm{cm}$ ] and shorter hospital stay [4 (2-8) vs. 6 (3-9) days] in patients

35 undergoing laparoscopy were significantly noted, respectively $(\mathrm{P}<0.01)$. No differences were

36 observed in age, operative time, and blood loss between both groups. The surgeries performed

37 were mostly detorsion with cystectomy and adnexectomy. The most common pathology was a

38 simple ovarian cyst, followed by teratoma. Regarding the surgical types, older age is the only

39 risk factor for radical surgery.

40 Discussion. Acute onset of abdominal pain with a presenting ovarian tumor is the most common

41 feature of adnexal torsion. Laparoscopic surgical group showed a small tumor size and a short

42 hospital stay than laparotomy. Older age is the risk factor for radical surgery. 


\section{Introduction}

45

46

47

48

49

50

51

52

53

54

55

56

57

58

59

60

\section{Methods}

62

63

64

65 66

62

Adnexal torsion is a gynecologic emergency that requires surgical treatment (Huang \& Wang, 2011; Huang, Hong \& Ding, 2017). It is defined as twisting of the ovary, fallopian tube, or adnexal mass, inducing adnexal torsion. Partial or complete rotation of the ovarian vascular pedicle obstructs venous outflow and arterial inflow (Chang, Bhatt \& Dogra, 2008). Both benign and malignant lesions of the ovary may be the leading causes of adnexal torsion.

Surgical intervention is the gold standard for diagnosis and treatment of adnexal torsion.

Conventionally, a twisted ovary or adnexa is excised completely (Houry \& Abbott, 2001). However, adnexa-sparing surgery has emerged as an alternative (Ding \& Chen, 2005; Spinelli et al., 2013; Nair, Joy \& Nayar, 2014; Ding \& Chang, 2016). Conservative surgery such as detorsion with cystectomy or cyst aspiration is preferred to preserve adnexal function. A previous study revealed that $51.4 \%$ of patients presenting to the emergency room were diagnosed with adnexal torsion (Lo et al., 2008).

Therefore, this study investigated the clinical characteristics of women with adnexal torsion in eastern Taiwan and compared the surgical outcomes of laparotomy and laparoscopy. We also calculate the risk factor for radical surgery.

This retrospective study analyzed the discharge data of women diagnosed with surgically proven adnexal torsion at Hualien Tzu Chi Hospital from January 1, 2010, to September 31, 2015. This study was approved by the Research Ethics Committee of Hualien Tzu Chi Hospital (IRB107-20-B). The Ethics Committee waived the need for informed consent from participants of this study. 
All patients diagnosed with adnexal torsion had records of the International Classification

68

of Diseases, Ninth Revision, Clinical Modification (ICD-9-CM) code 620.5 in their discharge notes. A total of 45 women were enrolled into our study, and 42 were diagnosed with adnexal torsion after surgery. Three patients did not receive surgical intervention because they refused surgical intervention, were lost to follow-up, or opted to receive medical treatment. Information on clinical characteristics, including age, medical history, operative time, and surgical methods, was obtained from patients' electronic medical records. Abdominal pain was defined as diffuse pain in the lower abdomen. In addition, surgical findings and pathological reports were obtained. The surgical routes were laparotomy and laparoscopy. The surgical methods for the management of adnexal torsion were cystectomy, adnexectomy, and detorsion.

Statistical analyses were performed using SPSS version 25 (IBM, New York, NY, USA). All continuous variables are presented as median (range). All categorical variables are presented as numbers (percentage). Mann-Whitney U test was used to compare the average of variables between two groups to determine the association between two continuous variables. Fisher's exact test was used to determine the difference between two categorical variables. Logistic regression was used to determine the odds ratio in the radical surgery group compared to the conservative surgery group. A $P$ value of $<0.05$ was considered statistically significant.

\section{Results}

A total of 42 patients were surgically diagnosed with adnexal torsion during the study period. Table 1 illustrates the symptoms and signs of patients with adnexal torsion. The laparoscopy and laparotomy groups included 27 and 15 patients, respectively. In both groups, the most common symptom was lower abdominal pain $(95.2 \%)$, followed by nausea and vomiting 
90 experienced by three and five patients in the laparoscopy and laparotomy groups, respectively.

91 Regarding other symptoms, one patients in the laparoscopy group developed urinary symptoms,

92 and two in the laparotomy group developed diarrhea. On examination, adnexal masses (100\%)

93 were noted in all patients. Four patients in the laparoscopy group and two in the laparotomy

94 group had leukocytosis. One patient in the laparotomy group had fever, and one in each group

95 had peritoneal signs. In our series, adnexal torsion was suspected in $64.4 \%$ of patients.

The median time (range) from symptom onset to seeking medical help was 12 (0-36)

97 and 24 (3-96) hours in the laparoscopy and laparotomy groups, respectively ( $\mathrm{p}=0.03$, Table 2).

98 The median time (range) from admission to surgery was $1.5(1-11.5)$ and $1.0(1-11)$ hours in the

99 laparoscopy and laparotomy groups, respectively. The median time (range) from gynecologic

100 evaluation to surgery was 2.0 (1-11) and 2.0 (1-11) hours in the laparoscopy and laparotomy

101 groups, respectively.

102 Table 3 presents the pathological findings of adnexal torsion. The most frequent 103 pathology was a simple cyst $(n=17,13$ and 4 in the laparoscopy and laparotomy groups, 104 respectively), followed by mature cystic teratoma $(\mathrm{n}=10,6$ and 4 in the laparoscopy and 105 laparotomy groups, respectively). The remaining pathologies were endometrioma, fibroma, 106 complex ovarian cyst and ovarian necrosis.

107 Table 4 provides a comparison of the surgical characteristics of patients who underwent 108 laparotomy or laparoscopy. The median (range) age of patients was 31 (13-76) and 41 (12-82)

109 years in the laparoscopy and laparotomy groups, respectively. The median (range) operative time 110 was 64 (20-200) and 70 (45-168) minutes in the laparoscopic and laparotomy groups, 111 respectively $(P=0.50)$. The median (range) blood loss was $50(50-500) \mathrm{ml}$ and $50(50-400) \mathrm{ml}$ 112 in the laparoscopy and laparotomy groups, respectively $(P=0.30)$. The median (range) tumor 
113 size was $7(4.2-10)$ and $10(7-17) \mathrm{cm}$ in the laparoscopy and laparotomy groups, respectively $(P$

$114<0.01)$. The median hospital stay was significantly shorter in the laparoscopy group than in the

115 laparotomy group ( 4.0 vs. 6.0 days, $P<0.01)$. The total number of cases managed by cystectomy

116 was 12, in which 10 and 2 cases were managed by laparoscopy and laparotomy, respectively

$117(P=0.09)$. The total number of cases managed by adnexectomy was 27 , in which 15 and 12 cases

118 were managed by laparoscopy and laparotomy, respectively $(P=0.10)$. Other two surgeries were 119 drainage and fixation by laparotomy.

120 Table 5 compared the basic characteristics, surgical, and pathological parameters between

121 conservative and radical surgery groups. We found the age was significant different between the 122 both groups $(\mathrm{P}=0.001)$. Older age was noted in radical surgery group. The other parameters was 123 no difference between both groups.

124 Table 6 calculated the odds ratio between between conservative and radical surgery 125 groups. We found older age is the risk factor for radical surgery [adjusted odds ratio (95\% $126 \mathrm{CI})=1.14(1.04-1.24), \mathrm{p}=0.004]$. Patients with nausea or vomiting revealed a low risk for radical 127 surgery (adjusted odds ratio $(95 \% \mathrm{CI})=0.02(0.00-0.97), \mathrm{p}=0.048)$.

129 Discussion

130 In our series, $64.4 \%$ of patients were suspected to have adnexal torsion. In other reports, the 131 incidence of suspected cases ranges from $18 \%$ to $62 \%$ before surgery (Cohen et al., 2001; Houry $132 \&$ Abbott, 2001; Oelsner et al., 2003). Suspicion of adnexal torsion is the key to early diagnosis 133 (Cohen et al., 2001). Adnexal torsion should be suspected in patients with a history of an 134 enlarged ovary or pelvic surgery complicated with abdominal pain (Houry \& Abbott, 2001). 
135 Tubal ligation is the most frequent surgical history in $40 \%$ of cases with adnexal torsion (Houry $136 \&$ Abbott, 2001).

137 Table 7 compared the current study to the previous literatures. Abdominal pain accounted 138 for the most presenting symptoms. Adnexal torsion was mostly happened at the Rt side. The 139 tumor size was mostly between $5-10 \mathrm{~cm}$. Laparoscopic surgery was the most surgical type. The 140 proportion of conservative or radical surgery was variant in different studies. In our study, we 141 found the older age is the risk factor for radical surgery. We speculated, for young patients, the 142 conservation of ovary is important for their future fertility. Thus, conservative surgery is largely 143 performed for young patients with ovarian torsion.

The study regarding fertility after ovarian torsion surgery is lacking. One report showed 145 patients with one ovary (mostly by oophorectomy due to ovarian torsion or other pathology) did 146 not affect the reproductive capability (Lass, 1999). But they have a shorter reproductive life span 147 due to less primordial follicles (Lass, 1999).

Objective findings are variable and are rarely significant in patients with adnexal torsion. A study of 179 patients with adnexal torsion showed leukocytosis and fever in $20.1 \%$ and $7.8 \%$ 150 of the patients (Nair, Joy \& Nayar, 2014). In our study, one patient had a fever (2.3\%) and six 151 patients had leukocytosis $(14.2 \%)$.

152 The sensitivity of pelvic ultrasound for diagnosing adnexal torsion ranges from $40 \%$ to 153 75\% (Mashiach et al., 2011). Twisted adnexal masses are often midline and located anterior to 154 the uterus; other findings include a cystic, solid, or complex mass with or without pelvic free 155 fluid and thickening of the wall with cystic hemorrhage (Mashiach et al., 2011). A previous 156 study found adnexal tumors larger than $5 \mathrm{~cm}$ in $88.4 \%$ of patients with adnexal torsion (Nair, Joy 157 \& Nayar, 2014). The whirlpool sign over the vessel pedicle has been reported to be a sign of 
158 adnexal torsion (Vijayaraghavan, 2004). In our study, the absence of blood flow showed low 159 sensitivity for diagnosing adnexal torsion.

160 In the present study, the most common pathology was a simple ovarian cyst, followed by 161 teratoma. Ashwal et al. also showed that the most common pathology was a simple cyst (Ashwal 162 et al., 2015). However, Lo et al. found that teratoma was the most common pathology (Lo et al., 163 2008).

Multiple tumor markers, such as AFP (alpha-fetoprotein), CEA (carcinoembryonic antigen), HCG (human chorionic gonadotropin), and CA125, have been used for diagnosing 166 ovarian neoplasms. CA125 is used for diagnosing epithelial ovarian tumors; however, it shows 167 poor sensitivity and specificity (Moss, Hollingworth \& Reynolds, 2005). In addition, CA125 levels are elevated in other benign conditions such as adenomyosis and endometriosis 169 (Ghaemmaghami, Karimi Zarchi \& Hamedi, 2007). One case study reported the association between elevated CA125 levels and adnexal torsion (McCarthy et al., 2010). However, in an emergency setting, CA125 results cannot be rapidly obtained. Therefore, we did not routinely determine CA125 levels in our adnexal torsion cases.

$\mathrm{C}$ reactive protein $(\mathrm{CRP})$ has been reported as a novel marker of adnexal torsion 174 (Tobiume et al., 2011; Damigos, Johns \& Ross, 2012; Bakacak et al., 2015; Bolli et al., 2017). In 175 an animal experiment, after adnexal ischemia, the plasma CRP level was found to be elevated 176 (Bakacak et al., 2015). In a previous study, a CRP level of $<0.3 \mathrm{mg} / \mathrm{dL}$ was correlated with a 177 favorable prognosis of ovarian conservation in adnexal torsion (Tobiume et al., 2011). However, 178 in our study, we did not routinely evaluate CRP levels. pain and enlarged adnexal masses (Cohen et al., 2001). In our patients, the time from admission 
181 to surgery was 3 hours, which was shorter than the time reported by Ashwal of 4.6 hours 182 (Ashwal et al., 2015).

183 In our study, no significant difference was observed in operative time between the 184 laparoscopy and laparotomy groups. Lo et al. also found no significant difference in operative 185 time between laparoscopy and laparotomy groups (Lo et al., 2008).

186 The only significant factor for choosing surgical route is tumor size (Lo et al., 2008). In 187 our series, the mean diameter of adnexal tumors was 6.9 and $10.4 \mathrm{~cm}$ in the laparoscopy and 188 laparotomy groups, respectively $(P<0.01)$. Significantly smaller ovarian cysts were noted in the 189 laparoscopy group than in the laparotomy group.

Although adnexal torsion occurs in all age groups, it is most commonly observed in reproductive age groups (Tsafrir et al., 2012; Vijayalakshmi et al., 2014). In this study, most 192 patients were postmenarchal, and eight women were postmenopausal.

In our study, younger patients received laparoscopy (33.6 vs. 41.0 years, $P=0.18$ ). A previous study also showed no difference in age between the laparoscopy and laparotomy groups (30 vs. 32 years). Cosmetic reasons may affect the chosen surgical route such as minimal invasive laparoscopy (Lee et al., 2010). The other reason is that ovarian malignancy is more often suspected in older patients, who may choose laparotomy (Moorman et al., 2008).

Significantly shorter length of hospital stay was noted in the laparoscopy compared to the 199 laparotomy group (4.0 vs 5.4 days, $\mathrm{p}<0.01$ ). This observation is consistent with the previous 200 reports (Lo et al., 2008; Grammatikakis et al., 2015).

201

We have shown that laparoscopic detorsion and cystectomy are feasible in adults and 202 pregnant women with adnexal torsion (Ding \& Chen, 2005; Ding \& Chang, 2016). Detorsion 
203 carries no risk of thrombosis (Ashwal et al., 2015; Huang, Hong \& Ding, 2017). In recent years, 204 detorsion without cystectomy or adnexectomy has become more prevalent (Ashwal et al., 2015). 205 In a previous study on a patient with a benign tumor, the potential for ovary conservation 206 was found to be greater in adnexal torsion cases with a short period from the onset of abdominal 207 pain to surgery (Tobiume et al., 2011). In our study, we performed detorsion with ovarian 208 cystectomy irregardless of tumor size. Moreover, a benign ovarian pathology should be obtained 209 during surgery (Jeon et al., 2017).

210 Previous studies have shown that ovarian morphology and function are restored to normal 211 after detorsion (Galinier et al., 2009; Geimanaite \& Trainavicius, 2013; Parelkar et al., 2014). 212 Moreover, studies have suggested that conservative treatment of adnexal torsion is safe. After 213 adnexal detorsion, menstruation and normal ovarian morphology were restored in all our 214 premenopausal patients.

215 The recurrence rate after detorsion is remained unknown. One report revealed $63 \%$ and $2168.7 \%$ recurrence rates in the twisted normal adnexa and twisted abnormal adnexa, respectively 217 (Pansky et al., 2007). There are several methods could prevent recurrence including 218 oophoropexy (Pansky et al., 2007) and oral contraceptives (Fee, Kanj \& Hoefgen, 2017). 219 However, both methods lack long term follow-up study.

221 Conclusions

In conclusion, the early diagnosis and intervention of adnexal torsion are crucial. Acute 223 onset of abdominal pain with a presenting adnexal tumor is the most common feature of adnexal 224 torsion.Laparoscopic surgical group showed a small tumor size and a short hospital stay than 225 laparotomy. Older age is the risk factor for radical surgery. 


\section{Acknowledgement}

228 The authors thank Dr. Jon-Son Kuo for English editing. We thank Wallace Academic Editing 229 group for English polishment.

230

231

232

233

234

235

236

237

238

239

240

241

242

243

244

245

246

247

248

249

250

251

\section{References}

Ashwal E., Hiersch L., Krissi H., Eitan R., Less S., Wiznitzer A., Peled Y. 2015. Characteristics and Management of Ovarian Torsion in Premenarchal Compared With Postmenarchal Patients. Obstetrics and gynecology 126:514-520.

Bakacak M., Köstü B., Ercan Ö., Bostancı MS., Kıran G., Aral M., Çıralık H., Serin S. 2015. Highsensitivity C-reactive protein as a novel marker in early diagnosis of ovarian torsion: an experimental study. Archives of gynecology and obstetrics 291:99-104.

Bolli P., Schädelin S., Holland-Cunz S., Zimmermann P. 2017. Ovarian torsion in children: Development of a predictive score. Medicine 96:e8299.

Chang HC., Bhatt S., Dogra VS. 2008. Pearls and pitfalls in diagnosis of ovarian torsion. Radiographics: a review publication of the Radiological Society of North America, Inc 28:1355-1368.

Cohen SB., Weisz B., Seidman DS., Mashiach S., Lidor AL., Goldenberg M. 2001. Accuracy of the preoperative diagnosis in 100 emergency laparoscopies performed due to acute abdomen in nonpregnant women. The Journal of the American Association of Gynecologic Laparoscopists 8:9294.

Damigos E., Johns J., Ross J. 2012. An update on the diagnosis and management of ovarian torsion. Obstetrics and gynecology 14:229-236.

Ding D-C., Chang Y-H. 2016. Laparoendoscopic single-site surgical cystectomy of a twisted ovarian dermoid cyst during early pregnancy: A case report and literature review. Gynecol Minim Invasive Ther 5:173-177. 
252 Ding D-C., Chen SS. 2005. Conservative laparoscopic management of ovarian teratoma torsion in a 253 young woman. Journal of the Chinese Medical Association: JCMA 68:37-39.

254 Fee EK., Kanj RV., Hoefgen HR. 2017. Recurrent ovarian torsion in an adolescent after oophoropexy. 255 Journal of Pediatric Surgery Case Reports 19:22-24.

256 Galinier P., Carfagna L., Delsol M., Ballouhey Q., Lemasson F., Le Mandat A., Moscovici J., Guitard J., 257 Pienkowski C., Vaysse P. 2009. Ovarian torsion. Management and ovarian prognosis: a report of 45 $258 \quad$ cases. Journal of pediatric surgery 44:1759-1765.

259 Geimanaite L., Trainavicius K. 2013. Ovarian torsion in children: management and outcomes. Journal of 260 pediatric surgery 48:1946-1953.

261 Ghaemmaghami F., Karimi Zarchi M., Hamedi B. 2007. High levels of CA125 (over 1,000 IU/ml) in 262 patients with gynecologic disease and no malignant conditions: three cases and literature review. Archives of gynecology and obstetrics 276:559-561.

264

265

266

267

268

269

270

271

272

273

274

275

276

277

Grammatikakis I., Trompoukis P., Zervoudis S., Mavrelos C., Economides P., Tziortzioti V., Evangelinakis N., Kassanos D. 2015. Laparoscopic treatment of 1522 adnexal masses: an 8-year experience. Diagnostic and therapeutic endoscopy 2015:979162.

Houry D., Abbott JT. 2001. Ovarian torsion: a fifteen-year review. Annals of emergency medicine 38:156-159.

Huang C., Hong M-K., Ding D-C. 2017. A review of ovary torsion. Ci ji yi xue za zhi=Tzu-chi medical journal 29:143-147.

Huang B-S., Wang P-H. 2011. Ovarian torsion during pregnancy. Taiwanese journal of obstetrics \& gynecology 50:409-410.

Jeon H., Ryu A., Seo H-G., Jang S-H. 2017. Ovarian torsion of mixed epithelial tumor misdiagnosed as a malignancy in postmenopausal woman: A case report. Medicine 96:e8207.

Lass A. 1999. The fertility potential of women with a single ovary. Human reproduction update 5:546-

Lee Y-Y., Kim T-J., Kim C-J., Park HS., Choi CH., Lee J-W., Lee J-H., Bae D-S., Kim B-G. 2010. 
278

279

280

281

282

283

284

285

286

287

288

289

290

291

292

293

294

295

296

297

298

299

300

301

302

303

Single port access laparoscopic adnexal surgery versus conventional laparoscopic adnexal surgery: a comparison of peri-operative outcomes. European journal of obstetrics, gynecology, and reproductive biology 151:181-184.

Lo L-M., Chang S-D., Horng S-G., Yang T-Y., Lee C-L., Liang C-C. 2008. Laparoscopy versus laparotomy for surgical intervention of ovarian torsion. The journal of obstetrics and gynaecology research 34:1020-1025.

Mashiach R., Melamed N., Gilad N., Ben-Shitrit G., Meizner I. 2011. Sonographic diagnosis of ovarian torsion: accuracy and predictive factors. Journal of ultrasound in medicine: official journal of the American Institute of Ultrasound in Medicine 30:1205-1210.

McCarthy JD., Erickson KM., Smith YR., Quint EH. 2010. Premenarchal ovarian torsion and elevated CA-125. Journal of pediatric and adolescent gynecology 23:e47-50.

Moorman PG., Calingaert B., Palmieri RT., Iversen ES., Bentley RC., Halabi S., Berchuck A., Schildkraut JM. 2008. Hormonal risk factors for ovarian cancer in premenopausal and postmenopausal women. American journal of epidemiology 167:1059-1069.

Moss EL., Hollingworth J., Reynolds TM. 2005. The role of CA125 in clinical practice. Journal of clinical pathology 58:308-312.

Nair S., Joy S., Nayar J. 2014. Five year retrospective case series of adnexal torsion. Journal of clinical and diagnostic research: JCDR 8:OC09-13.

Oelsner G., Cohen SB., Soriano D., Admon D., Mashiach S., Carp H. 2003. Minimal surgery for the twisted ischaemic adnexa can preserve ovarian function. Human reproduction 18:2599-2602.

Pansky M., Smorgick N., Herman A., Schneider D., Halperin R. 2007. Torsion of normal adnexa in postmenarchal women and risk of recurrence. Obstetrics and gynecology 109:355-359.

Parelkar SV., Mundada D., Sanghvi BV., Joshi PB., Oak SN., Kapadnis SP., Shetty S., Athawale H., Multani P. 2014. Should the ovary always be conserved in torsion? A tertiary care institute experience. Journal of pediatric surgery 49:465-468.

Spinelli C., Buti I., Pucci V., Liserre J., Alberti E., Nencini L., Alessandra M., Lo Piccolo R., Messineo A. 
304 2013. Adnexal torsion in children and adolescents: new trends to conservative surgical approach -305 our experience and review of literature. Gynecological endocrinology: the official journal of the 306 International Society of Gynecological Endocrinology 29:54-58.

307 Tobiume T., Shiota M., Umemoto M., Kotani Y., Hoshiai H. 2011. Predictive factors for ovarian necrosis 308 in torsion of ovarian tumor. The Tohoku journal of experimental medicine 225:211-214.

309 Tsafrir Z., Hasson J., Levin I., Solomon E., Lessing JB., Azem F. 2012. Adnexal torsion: cystectomy and 310 ovarian fixation are equally important in preventing recurrence. European journal of obstetrics, 311 gynecology, and reproductive biology 162:203-205.

312 Vijayalakshmi K., Reddy GMM., Subbiah VN., Sathiya S., Arjun B. 2014. Clinico-pathological profile of 313 adnexal torsion cases: a retrospective analysis from a tertiary care teaching hospital. Journal of $314 \quad$ clinical and diagnostic research: JCDR 8:OC04-7.

315 Vijayaraghavan SB. 2004. Sonographic whirlpool sign in ovarian torsion. Journal of ultrasound in $316 \quad$ medicine: official journal of the American Institute of Ultrasound in Medicine 23:1643-9; quiz $317 \quad 1650-1$.

318

319

320

321

322

323

324

325

326

327

328 


\section{Table 1 (on next page)}

Preoperative symptoms and signs associated with adnexal torsion $(n=42)$ 
Table 1. Preoperative symptoms and signs associated with adnexal torsion $(n=42)$

\begin{tabular}{|l|c|c|c|}
\hline & Laparoscopy $(\mathrm{n}=27)$ & $\begin{array}{c}\text { Laparotomy } \\
(\mathrm{n}=15)\end{array}$ & P-value \\
\hline Ovarian or pelvic mass & 27 & 15 & \\
\hline Pelvic pain & 26 & 14 & 0.59 \\
\hline Nausea and vomiting & 5 & 3 & 0.60 \\
\hline Peritoneal sign & 1 & 1 & 059 \\
\hline WBC $>12000$ & 4 & 2 & 0.63 \\
\hline Fever & 0 & 1 & 0.35 \\
\hline Urinary symptoms & 1 & 0 & 0.64 \\
\hline Diarrhea & 0 & 2 & 0.15 \\
\hline p-value : Fisher's exact test & & & \\
\hline
\end{tabular}




\section{Table 2 (on next page)}

Time interval between variables 
1

Table 2. Time interval between variables

\begin{tabular}{|l|c|c|c|}
\hline & $\begin{array}{l}\text { Laparoscopy } \\
(\mathrm{n}=27) \\
\text { Median (range) }\end{array}$ & $\begin{array}{l}\text { Laparotomy } \\
(\mathrm{n}=15) \\
\text { Median (range) }\end{array}$ & P-value \\
\hline $\begin{array}{l}\text { From symptom onset to ED } \\
\text { admission (hr) }\end{array}$ & $12(0-36)$ & $24(3-96)$ & $0.03^{*}$ \\
\hline From admission to surgery (hr) & $1.5(1-11.5)$ & $1.0(1-11)$ & 0.81 \\
\hline $\begin{array}{l}\text { From gynecologic evaluation to } \\
\text { surgery (hr) }\end{array}$ & $2.0(1-11)$ & $2.0(1-11)$ & 0.85 \\
\hline
\end{tabular}

p-value : Mann-Whitney U test.

ED: emergency department

2 


\section{Table $\mathbf{3}$ (on next page)}

Pathological diagnosis of the adnexal tumor 
Table 3. Pathological diagnosis of the adnexal tumor.

\begin{tabular}{|l|c|c|c|}
\hline & Laparoscopy $(\mathrm{n}=27)$ & Laparotomy $(\mathrm{n}=15)$ & P-value \\
\hline Simple cyst & 13 & 4 & 0.15 \\
\hline Mature cystic teratoma & 6 & 4 & 0.51 \\
\hline Endometrioma & 4 & 1 & 0.40 \\
\hline Fibroma or fibrothecoma & 0 & 4 & $0.01 *$ \\
\hline Necrosis of ovary & 1 & 0 & 0.64 \\
\hline Complex cyst & 3 & 2 & 0.59 \\
\hline
\end{tabular}

p-value : Fisher's exact test 


\section{Table 4 (on next page)}

Surgical characteristics in patients with adnexal torsion underwent laparoscopy and laparotomy 
1

Table 4. Surgical characteristics in patients with adnexal torsion underwent laparoscopy and laparotomy

\begin{tabular}{|l|c|c|c|}
\hline & $\begin{array}{l}\text { Laparoscopy (n=27) } \\
\text { Median (range) }\end{array}$ & $\begin{array}{l}\text { Laparotomy (n=15) } \\
\text { Median (range) }\end{array}$ & P-value \\
\hline Age (year) & $31(13-76)$ & $41(12-82)$ & 0.26 \\
\hline Surgical time (minute) & $64(20-200)$ & $70(45-168)$ & 0.50 \\
\hline Blood loss (mL) & $50(50-500)$ & $50(50-400)$ & 0.30 \\
\hline Tumor size (cm) & $7(4.2-10)$ & $10(7-17)$ & $<0.01^{*}$ \\
\hline Hospital stay (day) & $4(2-8)$ & $6(3-9)$ & $<0.01^{*}$ \\
\hline Surgery\$ n(\%) & $1(3.7 \%)$ & $0(0 \%)$ & 0.64 \\
\hline Detorsion and drainage & $10(37.0 \%)$ & $2(13.3 \%)$ & 0.09 \\
\hline Detorsion and cystectomy & $0(0 \%)$ & $1(6.6 \%)$ & 0.35 \\
\hline Detorsion and fixation & $15(55.6 \%)$ & $12(80.0 \%)$ & 0.10 \\
\hline $\begin{array}{l}\text { Ovarian or adnexal } \\
\text { resection }\end{array}$ & & & \\
\hline
\end{tabular}

p-value : Mann-Whitney U test

$\$ p$-value: Fisher's exact test

2 


\section{Table 5 (on next page)}

Surgical characteristics in patients with ovarian torsion underwent radical or conservative surgery 
Table 5. Surgical characteristics in patients with ovarian torsion underwent radical or conservative surgery

\begin{tabular}{|c|c|c|c|}
\hline & $\begin{array}{l}\text { Radical surgery } \\
(\mathrm{n}=27) \\
\text { Median (range) }\end{array}$ & $\begin{array}{l}\text { Conservative surgery } \\
(\mathrm{n}=15) \\
\text { Median (range) }\end{array}$ & P-value \\
\hline Age (year) & $42(12-82)$ & $24(13-45)$ & $<0.01^{*}$ \\
\hline $\begin{array}{l}\text { Surgical time } \\
\text { (minute) }\end{array}$ & $70(29-190)$ & $60(30-200)$ & 0.66 \\
\hline Blood loss (mL) & $50(50-500)$ & $50(50-500)$ & 0.66 \\
\hline Tumor size $(\mathrm{cm})$ & $8.5(4.2-17)$ & $7.0(4.6-12)$ & 0.11 \\
\hline Hospital stay (day) & $5(2-9)$ & $4(2-7)$ & 0.11 \\
\hline \multicolumn{4}{|l|}{ Time interval } \\
\hline $\begin{array}{l}\text { From symptom onset } \\
\text { to ED admission (hr) }\end{array}$ & $12(0-48)$ & $12(1-96)$ & 0.76 \\
\hline $\begin{array}{l}\text { From admission to } \\
\text { surgery }(\mathrm{hr})\end{array}$ & $1.5(1-11)$ & $1(1-11.5)$ & 0.84 \\
\hline $\begin{array}{l}\text { From gynecologic } \\
\text { evaluation to surgery } \\
\text { (hr) }\end{array}$ & $2(1-11)$ & $2(1-11)$ & 0.97 \\
\hline Op type $[\mathrm{n}(\%)]$ & & & 0.1 \\
\hline Laparoscopy & $27(55.6 \%)$ & $12(80 \%)$ & \\
\hline Laparotomy & $12(44.4 \%)$ & $3(20 \%)$ & \\
\hline \multicolumn{4}{|l|}{ Tumor type (n) } \\
\hline Simple cyst & $9(33.3 \%)$ & $8(53.3 \%)$ & 0.17 \\
\hline $\begin{array}{l}\text { Mature cystic } \\
\text { teratoma }\end{array}$ & $6(22.2 \%)$ & $4(26.7 \%)$ & 0.51 \\
\hline Endometrioma & $4(14.8 \%)$ & $1(6.7 \%)$ & 0.4 \\
\hline $\begin{array}{l}\text { Fibroma or } \\
\text { fibrothecoma }\end{array}$ & $4(14.8 \%)$ & $0(0 \%)$ & 0.15 \\
\hline Necrosis of ovary & $1(3.7 \%)$ & $0(0 \%)$ & 0.64 \\
\hline \multicolumn{4}{|l|}{$\begin{array}{l}\text { Symptoms and signs } \\
\text { (n) }\end{array}$} \\
\hline $\begin{array}{l}\text { Ovarian or pelvic } \\
\text { mass }\end{array}$ & $27(100 \%)$ & $15(100 \%)$ & 1 \\
\hline Pelvic pain & $25(92.6 \%)$ & $15(100 \%)$ & 0.5 \\
\hline
\end{tabular}


Manuscript to be reviewed

\begin{tabular}{|l|c|c|c|}
\hline Nausea and vomiting & $3(11.1 \%)$ & $5(33.3 \%)$ & 0.09 \\
\hline Peritoneal sign & $2(7.4 \%)$ & $0(0 \%)$ & 0.4 \\
\hline WBC $>12000$ & $5(18.5 \%)$ & $1(6.7 \%)$ & 0.53 \\
\hline Fever & $1(3.7 \%)$ & $0(0 \%)$ & 0.39 \\
\hline Urinary symptoms & $0(0 \%)$ & $1(6.7 \%)$ & 0.35 \\
\hline Diarrhea & $1(3.7 \%)$ & $1(6.7 \%)$ & 1 \\
\hline
\end{tabular}


Table 6(on next page)

Factors associated with receiving oophorectomy $(n=42)$ 
Table 6. Factors associated with receiving oophorectomy $(n=42)$.

\begin{tabular}{|c|c|c|c|c|}
\hline & \multicolumn{2}{|c|}{ Crude } & \multicolumn{2}{|c|}{ Adjusted } \\
\hline & $\begin{array}{l}\text { Odds Ratio } \\
(95 \% \mathrm{CI})\end{array}$ & $\mathrm{p}$ value & $\begin{array}{l}\text { Odds Ratio } \\
(95 \% \mathrm{CI})\end{array}$ & $\mathrm{p}$ value \\
\hline Age & $\begin{array}{c}1.10 \\
(1.03 \text { to } 1.17)\end{array}$ & $0.004 *$ & $\begin{array}{c}1.14 \\
(1.04 \text { to } 1.24)\end{array}$ & $0.004 *$ \\
\hline Simple cyst(Y vs. N) & $\begin{array}{c}0.44 \\
(0.12 \text { to } 1.59)\end{array}$ & 0.210 & $\begin{array}{c}0.34 \\
(0.05 \text { to } 2.44)\end{array}$ & 0.284 \\
\hline $\begin{array}{l}\text { Mature cystic teratoma(Y } \\
\text { vs. N) }\end{array}$ & $\begin{array}{c}0.79 \\
(0.18 \text { to } 3.39)\end{array}$ & 0.746 & & \\
\hline Endometrioma(Y vs. N) & $\begin{array}{c}2.44 \\
(0.25 \text { to } 24.04)\end{array}$ & 0.446 & $\begin{array}{c}0.37 \\
(0.02 \text { to } 8.23)\end{array}$ & 0.532 \\
\hline $\begin{array}{l}\text { Fibroma or } \\
\text { fibrothecoma(Y vs. N) }\end{array}$ & $1.05 \mathrm{E} 9$ (NA) & 0.999 & & \\
\hline $\begin{array}{l}\text { Necrosis of ovary(Y vs. } \\
\text { N) }\end{array}$ & 9.32E8 (NA) & 1.000 & & \\
\hline \multicolumn{5}{|l|}{ Symptoms and signs } \\
\hline $\begin{array}{l}\text { Ovarian or pelvic mass(Y } \\
\text { vs. N) }\end{array}$ & NA & NA & & \\
\hline Pelvic pain(Y vs. N) & 0.00 (NA) & 0.999 & & \\
\hline $\begin{array}{l}\text { Nausea and vomiting }(Y \\
\text { vs. N) }\end{array}$ & $\begin{array}{c}0.25 \\
(0.05 \text { to } 1.25)\end{array}$ & 0.092 & $\begin{array}{c}0.02 \\
(0.00 \text { to } 0.97)\end{array}$ & $0.048^{*}$ \\
\hline Peritoneal sign(Y vs. N) & 9.69E8 (NA) & 0.999 & & \\
\hline WBC $>12000(Y$ vs. N) & $\begin{array}{c}3.18 \\
(0.34 \text { to } 30.16)\end{array}$ & 0.313 & $\begin{array}{c}42.03 \\
(0.87 \text { to } \\
2020.68)\end{array}$ & 0.059 \\
\hline Fever(Y vs. N) & 9.32E8 (NA) & 1.000 & & \\
\hline $\begin{array}{l}\text { Urinary symptoms(Y vs. } \\
\text { N) }\end{array}$ & 0.00 (NA) & 0.999 & & \\
\hline Diarrhea(Y vs. N) & $\begin{array}{c}0.54 \\
(0.03 \text { to } 9.28)\end{array}$ & 0.670 & & \\
\hline \multicolumn{5}{|c|}{$\begin{array}{l}\text { Data are presented as Odds ratio }(95 \% \mathrm{CI}) \\
* \text { p-value }<0.05 \text { was considered statistically significant after test }\end{array}$} \\
\hline
\end{tabular}


Table 7 (on next page)

Comparison of present study to the previous studies 
Table 7. Comparison of present study to the previous studies.

\begin{tabular}{|c|c|c|c|c|c|}
\hline & Our study & $\begin{array}{l}\text { Nair et al. } \\
2014\end{array}$ & $\begin{array}{l}\text { Vijayalaks } \\
\text { hmi et al. } \\
2014\end{array}$ & $\begin{array}{l}\text { Spinell et } \\
\text { al. } 2012\end{array}$ & $\begin{array}{l}\text { Vijayaragha } \\
\text { van et al. } \\
2004\end{array}$ \\
\hline No. of patients & 42 & 70 & 18 & 30 & 21 \\
\hline Age & $12-82 \mathrm{yrs}$ & $11-91 \mathrm{yrs}$ & $25-72 \mathrm{yrs}$ & $\begin{array}{c}\text { 2months- } \\
18 \mathrm{yrs}\end{array}$ & $7-69 \mathrm{yrs}$ \\
\hline Pregnancy & $6.6 \%$ & $2.9 \%$ & & & $4.7 \%$ \\
\hline Abdominal pain & $95.2 \%$ & $95.7 \%$ & $77.8 \%$ & $100 \%$ & $100 \%$ \\
\hline Nausea/vomiting & $19 \%$ & $65.7 \%$ & $27.8 \%$ & $56.7 \%$ & \\
\hline Fever & $2.3 \%$ & $12.9 \%$ & $5.6 \%$ & $20 \%$ & \\
\hline Leukocytosis & $14.2 \%$ & $44 \%$ & & $63.3 \%$ & \\
\hline $\begin{array}{l}\text { Doppler diagnosis of } \\
\text { torsion }\end{array}$ & & $25.7 \%$ & & $63 \%$ & $95.2 \%$ \\
\hline Free fluids in pelvis & & $23.8 \%$ & & $26.7 \%$ & \\
\hline Right side & $51.1 \%$ & $55.7 \%$ & $50 \%$ & $70 \%$ & \\
\hline Left side & $40.0 \%$ & $42.9 \%$ & $38.9 \%$ & $30 \%$ & \\
\hline Bilateral & $2.2 \%$ & $1.4 \%$ & $11.1 \%$ & & \\
\hline Size $<5 \mathrm{~cm}$ & $11.1 \%$ & & & & \\
\hline Size $5 \sim 10 \mathrm{~cm}$ & $71.1 \%$ & $71.4 \%$ & $33.3 \%$ & & \\
\hline Size $>10 \mathrm{~cm}$ & $17.7 \%$ & $11.4 \%$ & $44.4 \%$ & & \\
\hline $\begin{array}{l}\text { Mature cystic } \\
\text { teratoma }\end{array}$ & $23.8 \%$ & $22.8 \%$ & $16.7 \%$ & $16.7 \%$ & $28.5 \%$ \\
\hline $\begin{array}{l}\text { Mucinous } \\
\text { cystadenoma }\end{array}$ & & $7.1 \%$ & $33.3 \%$ & $3.3 \%$ & $9.5 \%$ \\
\hline Serous cystadenoma & & $15.7 \%$ & $16.7 \%$ & & $47.6 \%$ \\
\hline Hemorrhagic necrosis & $2.3 \%$ & $30.4 \%$ & & & $9.5 \%$ \\
\hline Laparoscopy & $64.2 \%$ & $81.4 \%$ & & $40 \%$ & \\
\hline Laparotomy & $35.8 \%$ & $18.6 \%$ & & $60 \%$ & \\
\hline Conservative surgery & $35.8 \%$ & $54.3 \%$ & & $46.7 \%$ & \\
\hline Radical surgery & $64.2 \%$ & $45.7 \%$ & & $53.3 \%$ & \\
\hline
\end{tabular}

